\title{
Plasma Levels of Beta-endorphin and Serotonin in Response to Specific Spinal Based Exercises
}

\begin{abstract}
Exercises as the primary mode of treatment for low back disorders aim to achieve pain reduction, improvement in functional ability and quality of life of for low back disorder sufferers. However the biochemical events associated with the use of these exercises in terms of their effects on pain relieving neuropeptides have not been well established. This study was carried out to investigate the effects of spinal stabilisation, back extension and treadmill walking exercises on plasma levels of serotonin and beta-endorphin.

Twenty volunteers (10 males and 10 females) without low back pain
\end{abstract} participated in the study. They were randomly allocated either to one of the

\author{
Sokunbi O, PhD, MCSP', \\ Moore A, PhD, \\ GradDipPhys, FCSP, FMACP², \\ Watt $\mathbf{P}, \mathrm{PhD}^{3}$
}

1 Physiotherapy Department, College of Medicine,
University of Lagos.
${ }^{2}$ Clinical Research Centre for Health Professions,
University of Brighton.
${ }^{3}$ Chelsea School of Sport, University of Brighton. exercise groups, where participants carried out one of the spinal stabilisation, back extension and treadmill walking exercises or the control (no exercise) group. The main outcome measures used in this study were plasma levels of serotonin and beta-endorphin measured with Enzyme linked immuno absorbent assay (ELISA) technique.

The results of this study showed that spinal stabilisation and treadmill walking exercises produced significant increase in plasma serotonin levels $(P<0.05)$ however there were no significant changes in the plasma levels of beta-endorphin in all the exercise groups $(P>0.05)$.

It could be that biochemical effects associated with stabilisation and treadmill walking exercises therefore may involve production of serotonin and its release into the plasma.

KEY WORDS: SPINAL BASED EXERCISES, SEROTONIN, BETA-ENDORPHIN.

\section{INTRODUCTION}

Back pain is universal in humans and has been referred to as 20th century health care disaster (Waddell 1996). On average, low back disorders account for 65 million general practitioner consultations In the UK (CSAG 1994). The problem of low back disorder seems to be evident on a similar scale elsewhere in the world (Lapsely 1990). Although the prevalence of back pain has not increased significantly over the last 15 years, the degree of disability has, leading to rising demands of the cost of health care (Linton 1997). Exercise remains one of the most frequently prescribed treatments in the management of low back disorders (Rainville et al. 2004). It has received attention as a result in part of the lack of available drugs that can be used in the management of chronic back disorders over an extended period of time without risk of side effects or addiction (De Vries 1981). With this goal in mind exercises for low back disorders are typically designed around the goal of pain relief, strengthening the back increasing back flexibility, improving functional activities, cardiovascular endurance and general wellness (Waddell et al. 1992).

The efficacies of many forms of exercises on chronic low back disorder have been reported. A combination of isometric back exercises, general strength training, and a home exercise regime was shown to be effective in the management of chronic back disorders with results well maintained at six months follow up (Mannion et al.1999). However, Mannion et al's study did not include a control group and this questions the validity of their findings. A general endurance exercise was shown to be of greater benefit than specific exercises whose effects are aimed at the lumbar spine and better results were achieved with class based supervised exercise programs (Jadad et al.1998). On the contrary, a review, involving 39 randomised controlled trials on common therapeutic interventions for low back disorders showed evidence that extension based back exercises and stretching exercises in combination with isometric abdominal exercises are not any more effective in reducing pain and improving functional status than manipulation (VanTulder et al. 2000). Heterogeneity of the aetiology of low back pain of the subjects constituted a fundamental limitation to VanTulder et al's review.

A recent focus in physiotherapy management of chronic low back pain has been to identify specific muscles that are best able to stabilise the back and to carry out spinal stabilisation exercises to enhance those muscles whose primary functions is considered dynamic stability and segmental control of the spine. Results of some of the studies on common therapeutic intervention for LBP have shown a positive trend in favour of spinal stabilisation exercise treatment

\section{CORRESPONDENCE TO:}

Oluwaleke Sokunbi

Physiotherapy Department, College of Medicine,

University of Lagos

PMB 12003 Lagos, Nigeria

Tel: 00234(1)8051841724

E-mail: sogleke@yahoo.com 
programme (Goldby et al. 2006; Hides et al. 1996; O'Sullivan et al.1997). However, the main facilitation techniques behind the efficacy of these spinal stabilisation exercises in the management of LBP still remain uncertain and there have been various explanations by different authors as regards the efficacy of these exercises.

Exercise remains one of the strategies for the exploitation of descending control to alleviate pain via stimulation of opioidergic and serotonergic systems, but the effects of spinal based exercises commonly used in the management of LBP disorders on pain modulatory mechanisms via production beta-endorphin and serotonin appeared to have been subjected to little experimentation.

\section{PLASMA BETA-ENDORPHIN CHANGES IN EXERCISE}

Recently there has been interest in betaendorphins in relation to exercise as there appeared to be an association between exercises induced increase in circulating beta-endorphins and perception of pain (Jarmukli et al. 1999). Although there is evidence that physical exertion leads to increase in blood levels of beta-endorphins, the main physiological trigger responsible for stimulating the release of beta endorphin during exercise has not been clearly explained (Taylor et al. 1994). Results of many studies have suggested that betaendorphins are released in the sympathoadrenal and pituitary adrenocortical systems when the anaerobic threshold is reached during exercise training (Hoffman et al. 1996; McMurray et al. 1984; Sheps et al. 1988; Sheps et al. 1995). The anaerobic threshold is characterised by large amount of lactic acid in the circulatory system, when the process of production and removal are no longer in balance (Hoffman 1996; Jarmukli et al. 1999). Similarly, the dependence of beta-endorphin responses upon exercise intensity is a common finding. Most data show an increase in the blood beta-endorphin if the exercise intensity exceeds $60-80 \%$ V02 max in certain individuals and $90 \%$ V02max in most individuals (Carr et al. 1981; Farrell et al. 1987). Also, when the exercise intensity is high, duration of 30-60 seconds is enough to elevate plasma levels of beta-endorphin (Farrell et al.1987).

Four variants of dynamics in blood endorphin concentration during exercise have been reported: (1) an increase during the first 30 minutes of exercise followed by a decrease below the initial value, (2) a biphasic increase with peak values at 30th and 120th minutes of the exercise, (3) an increase only during the second hour of the exercise, (4) a decrease during the whole period of the exercise (Carr et al. 1981; Farrell et al. 1987; Viru et al. 1992). Concise explanation as to why these variants occurred has not been proffered; however, Carr et al. (1981) showed that in individuals with high levels of physical training such as endurance sportsmen, the most common variant was the biphasic. The first and the third variants have been reported in sportsmen when the exercise intensity was lower than envisaged (Viru et al. 1990). Decrease in the basal beta-endorphin through out the whole exercise was reported in sedentary individuals by Farrell et al. (1987).

\section{EXERCISE AND SEROTONERGIC SYSTEM}

It is generally accepted that serotonin is equally involved in the mechanism of action of exercise induced analgesia (Kema et al. 2000). Biosynthesis of serotonin in the human body involves hydroxylation of tryptophan (essential amino acid) by tryptophan hydroxylase to produce 5-hydroxytryptophan (5-HTP) and decarboxylation of 5-HTP by aromatic-L-amino acid decarboxylase to produce serotonin (Kema et al. 2000). It has been established that there are two pools of tryptophan in the blood tissue; one that is bound to platelets and the other that is free (Atkinson et al. 1999). Thus, it could be said that serotonin synthesis is dependent on free tryptophan availability. Consequently, processes that influence equilibrium between free tryptophan and platelets bound tryptophan will affect serotonin synthesis rate. The efflux of serotonin from platelets is increased by many factors including raised levels of adrenaline as occur during exercise and many other stress situations (Atkinson et al. 1999).

Surprisingly, the dose effects of exercise training of the plasma levels of serotonin appeared not to have been well investigated. However, Jensen et al.
(1995) reported a 4\% increase in serum serotonin concentration following an acute episode of exercise whereby normal subjects were exercised on bicycle ergometer for 15 minutes. Lechin et al. (2004) reported an increase by $15.9 \%$ in the level of plasma serotonin in healthy volunteers instructed to perform a treadmill exercise test consisting of 5 minutes walking exercises at $2 \mathrm{mph}$.

It seems that the effects of spinal based exercises on the plasma levels of serotonin and beta-endorphins have not been widely reported, such knowledge will be useful to optimize the therapeutic benefit of exercise induced analgesia in patients with LBP.

\section{OBJECTIVE OF THE STUDY}

The specific aim of this study was to investigate the changes in the concentration of beta-endorphin and serotonin in response to selected exercises (back extension, treadmill walking and stabilisation exercises) commonly used by physiotherapist in the management of LBP

The outcome of this study informed the author's choice of using one of these exercises in a large randomised controlled trial where the effects of frequency of application of the exercise on plasma levels of serotonin was investigated. The outcome of this study might also influence the choice of a particular type of exercise in the management of low back disorders.

\section{METHODS}

\section{Ethics approval}

Ethics approval for this study was obtained from the research Ethics committee of the University of Brighton prior to its commencement. The methodological flow chart is presented in figure 1.

\section{SUBJECTS}

Twenty subjects (10 males and 10 females) aged between 18 and 60 years were recruited to participate in this study. A sample size of 20 was considered appropriate. This figure was considered appropriate based on the report of similar studies on the effect of exercise on pain relieving peptides (Goldfrab et al.1997; Lechin et al. 2004; Sheps et al. 1988). 


\section{Inclusion criteria}

Subjects without history of low back pain were involved to ensure optimal muscle contraction unhindered by pain during exercise testing.

Subjects from the age of 16 years to 60 years were considered eligible for this study This decision was based on the report of an increasing prevalence of LBP from the second decades, reaching its maximum in the fifth and sixth decades.(Riihmaki et al. 1994).

\section{Exclusion criteria}

Participants were excluded from the study if they had a history of non-specific low back pain for at least 12 months prior to the commencement of the study. This was because an ongoing low back pain could potentially influenced plasma levels of beta- endorphins and serotonin (Sheps et al. 1988; Goldfrab et al.1997).

Other exclusion criteria include any medical or surgical conditions which might hinder exercise performance e.g. evidence of inflammatory joint disease and lower limb pathology, recent fracture of the spine, past history of operative intervention for lower back problems, metastatic diseases, anxiety neurosis and depressive symptomatology. Women who were pregnant and those within 3 days before and 3 days after their menstruating were also excluded as this phase of menstrual cycle could potentially influenced plasma levels of beta endorphins and serotonin (Sheps et al. 1988; Goldfrab et al.1997).

\section{Figure 1: Methodological flow chart}

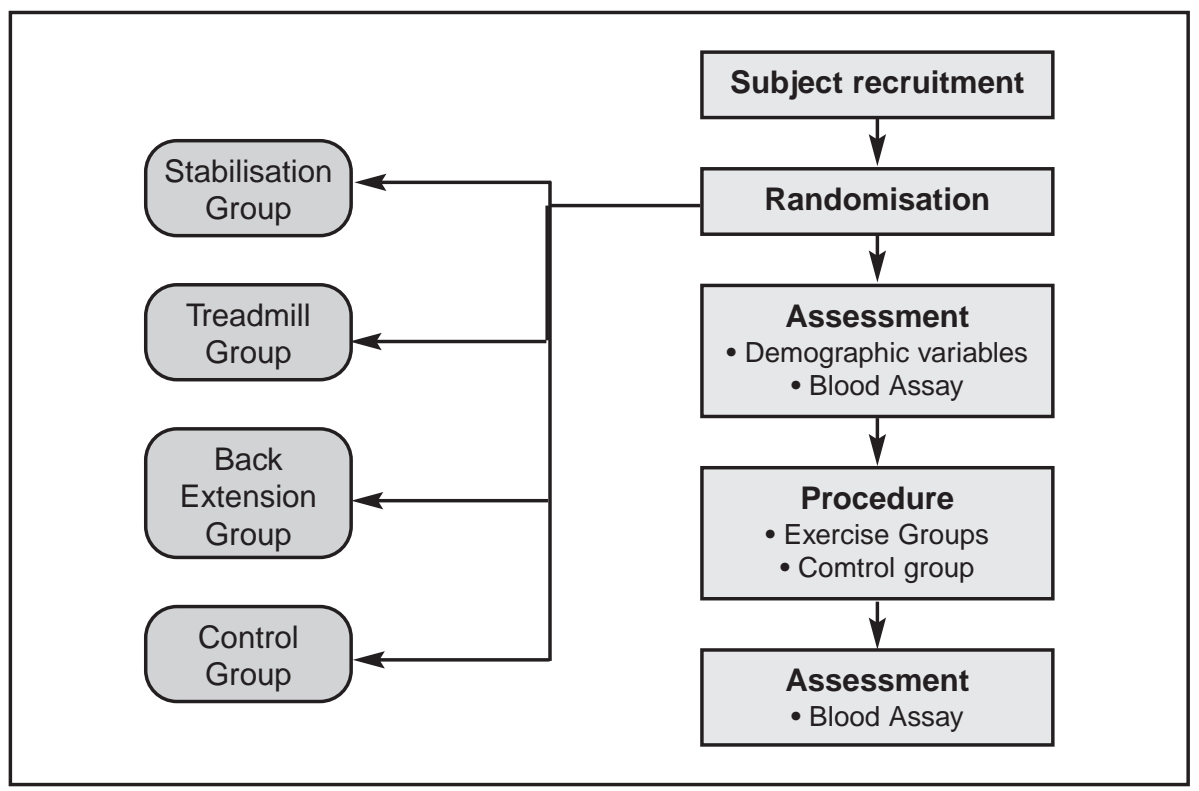

\section{RANDOMIZATION OF SUBJECTS INTO GROUPS}

Microsoft Excel 2000 was used to generate a list of randomised numbers which was used to randomly assign subjects into the control and three different exercise groups where they perform any one of the three exercise protocols i.e. spinal stabilisation exercise, back extension exercise, treadmill walk exercise. Six participants were randomised into stabilisation exercise group; five subjects each were randomised into Back extension exercise group and treadmill walk exercise group while four subjects were randomised into the control group.

A member of the University staff who was not involved in any other aspects of this study carried out the randomisation.

\section{ASSESSMENTS}

Written informed consent was obtained from the entire participants prior to initial assessments.

Participants were requested to refrain from smoking and taking caffeine and/ or alcohol for at least 12 hours before the exercise testing, because this may potentially influenced plasma concentration of serotonin and beta endorphins (Lechin et al. 2004). Participants were asked questions to ensure their compliance in this regard, prior to initial assessments.

Measurement of demographic variables such as age, weight $(\mathrm{kg})$, height (m) and body mass index, BMI $\left(\mathrm{kgm}^{-2}\right)$ was carried out. Weight, height and BMI

were measured and interpreted as previously reported by Berkow et al. (1992).

The outcome measures used in this study were plasma levels of betaendorphin and serotonin.

\section{ANALYSIS OF PLASMA LEVELS OF BETA- ENDORPHIN AND SEROTONIN}

Analysis of plasma levels of betaendorphin and serotonin was carried out using Enzyme Linked Immunoabsorbent Assay (ELISA). The analysis was carried out by one of the authors (PW). PW was not involved in any other procedural aspects of this study.

\section{Assay Kits}

The beta-endorphin kits was manufactured and supplied by MD Biosciences, division of Morwell diagnostic $\mathrm{GmbH}$ Zurich, Switzerland. Labor Diagnostika Nord GmbH Nordhorn, Germany manufactured the serotonin assay kit.

\section{Collection of blood samples}

In order to minimise the biochemical effects of the previous participants physical activity on the plasma levels of beta endorphins and serotonin, prior to exercise testing, on arrival, participants were requested to observe an initial period of 30 minutes rest in a supine lying position with pillow support under their head and knees (Lechin et al. 2004). Collection of blood samples and assaying for the plasma levels of betaendorphin and serotonin for all the subjects were carried out between 9.00am and 11.00am in order to control for the diurnal variation effects on plasma levels of beta-endorphin and serotonin.

Blood samples $(10 \mathrm{ml})$ was collected from the antecubital vein into the syringes after 30 minutes of bed rest in supine lying positions for all the subjects and then transferred into a tube containing ethylenediaminetriacetic acid (EDTA). The EDTA tube was gently rocked several times to prevent coagulation before being transferred to a centrifuge. The blood was centrifuged at $1600 x g$ for 15 minutes at $4^{\circ} \mathrm{C}$ and the plasma was collected and was kept at $20^{\circ} \mathrm{C}$ prior to extraction of peptide from the plasma.

Extraction of peptide from plasma The plasma obtained was then acidified 
with $1 \%$ trifluroacetic acid (TFA HPLC Grade) in $\mathrm{H}_{2} \mathrm{O}$ and centrifuged at 6000 to $17000 \mathrm{rpm}$ for 20 minutes at $4^{\circ} \mathrm{C}$. The acidified plasma was then loaded to a pre treated C-18 SEP COLUMN. The column was then washed with $1 \%$ trifluroacetic acid in $\mathrm{H}_{2} 0$. The peptide obtained was then eluted slowly with $60 \%$ acetonitrile (HPLC Grade) in $1 \%$ TFA. The eluant was evaporated to dryness and the dried extract was kept at $-2^{\circ} \mathrm{C}$ prior to the assay for plasma levels of serotonin and beta-endorphin using serotonin and beta-endorphin kits respectively.

\section{Sensitivity, intra and inter assay variation testing}

Prior to assay for plasma levels of serotonin and beta-endorphins, the sensitivity of the assay kits, intra and inter assay variation test was carried out by a blinded researcher. The sensitivity of beta-endorphin kit was $0.11 \mathrm{ng} / \mathrm{ml}$ with less than $5 \%$ intra assay variation and less than $14 \%$ inter assay variation. It has a cross reactivity of $100 \%$, and a range of $0-100 \mathrm{ng} / \mathrm{ml}$. The sensitivity of the serotonin kit was $5 \mathrm{ng} / \mathrm{ml}$ with less than $5 \%$ intra assay variation and $6 \%$ inter assay variation, it has a cross reactivity of a $100 \%$.

\section{PROCEDURES}

\section{Exercise groups}

After the initial blood collection, participants were requested to rest for a period of 5 minutes in order to monitor any cardiovascular changes that may affect their exercise performance during the exercise testing. Three types of exercises, treadmill walking, back extension and spinal stabilisation exercises were used in this study. The choice to use these exercises was based on the reports of some of the findings portraying their efficacies in the management of low back disorders (CSAG 1994; Goldby et al. 2006; Hides et al. 1996; O'Sullivan 1997; VanTulder 2000).

\section{Treadmill walking}

This exercise was performed on a treadmill (CASE 12, Marquette Electronic Co Milwaukee, W1 USA) using a modify Bruce protocol (Goldfrab et al. 1997). Participants were asked to carry out a 5-minute warm-up walk at $3.5 \mathrm{mph}$ and $2.5 \%$ grade for five minutes. This was then followed by a continuous multistage run. The speed of the run was adjusted by adding $14 \%$ of $3.5 \mathrm{mph}$ each minute after the first 5 minutes for a maximum period of 10 minutes. Criteria for stopping the exercise were leg fatigue, shortness of breath and/or finishing at 10 minutes (Goldfrab et al. 1997).

\section{Back extension exercise}

With the subjects lying prone on a plinth and the thighs and buttocks well stabilized with straps, subjects were instructed to lift up their head and chest away from the plinth as far as possible. The final position reached was held for 10 seconds. Subjects were requested to carry out a minimum of 8 and maximum of 15 repetitions of back extension exercise (Risch et al. 1993). Back extension exercise lasted for 5-10 minutes.

\section{Spinal stabilisation exercises}

The spinal stabilisation exercise protocol used in this study was similar to the one reported by Goldby et al. (2006). Prior to stabilisation exercise training, participants were shown a videotape. The aim of the videotape was to provide visual representation of how both the effective and ineffective musculature of the lumbar spine could affect spinal stability.

The videotape depicts a robotic model standing, walking and bending. The model illustrates pain on lifting when the spine is unstable. The local stabilising muscles i.e. transversus, multifidus, diaphragm and pelvic floor were then superimposed on the model and repeat the task of walking and bending again. This time the model experiences no pain reinforcing how these muscles support the spine and reduce pain (Goldby et al. 2006). The use of visual illustration in stabilisation exercise programme has been reported to assist patients to anatomically visualise the muscles they were trying to facilitate, enhancing mental concentration and so facilitating rehabilitation of the neural control subsystem (Smith 1998)

After the video illustrations, participants were instructed on how to identify the location of transversus abdominis and how to co-activate the contraction of the main muscles involved in spinal stabilisation i.e. transversus, multifidus, diaphragm and pelvic floor. Only those subjects who were able to demonstrate the ability to isolate, activate and hold the contraction of the local stabilising muscles were allowed to progress to the next phase of the exercise which was made up of six stages of stabilisation exercise procedure and in which participants were required to perform up to 5 minutes of an intensive stabilisation exercise at each of the stage. Stage wise progression of the stabilisation exercise protocol used in this study was as described by Goldby et al. (2006)

Stabilisation exercise protocol lasted for 45 minutes after which the video illustration was repeated again.

\section{Control Group}

Participants in the control group, following initial assessment and blood taken were asked to assume a supine lying position for 30 minutes, on a plinth with adequate pillow support underneath head, shoulder and knees, in a different room to that where the exercise testing was carried out. The choice of using a different room was considered necessary to enable the participants to feel more relaxed (Sheps et al. 1988).

\section{ASSESSMENTS}

Analysis of plasma levels of beta-endorphin and serotonin was repeated as described earlier:

I) Immediately after exercise for the participants in the exercise groups, and

II) Immediately after a period of 30 minutes of resting in supine position for the participants in the control group (Lechin et al. 2004; Sheps et al. 1988).

\section{STATISTICAL ANALYSIS}

Demographic variables and the data on plasma levels of beta-endorphin and serotonin were explored for normality of distribution. Plasma levels of betaendorphin and serotonin showed symmetrical distribution and were presented as mean and standard deviation. Comparison of the pre exercise and post exercise levels of beta endorphin and serotonin among the groups was carried out with one way analysis of variance while paired t-test was used to analyze 
for within group differences (post exercise Vs pre exercise). Statistical significance was accepted at 5\% level.

\section{RESULTS}

\section{The participants}

Twenty subjects (10 males, 10 females) among the students and staff of the University of Brighton volunteered to participate in this study. The physical characteristics for the study groups are listed in table 1 . Their average age was $30.8 \pm 3.2$ years while their average height, weight and BMI were $1.63 \pm 0.1 \mathrm{~m}$, $56.2 \pm 6.8 \mathrm{~kg}$ and $21.2 \pm 3.2 \mathrm{~kg} / \mathrm{m}^{2}$ respectively. There were no significant differences between the group in terms of age, weight, height and body mass index $(\mathrm{BMI})(\mathrm{P}>0.05)$.
Plasma levels of serotonin.

Plasma levels of serotonin of the participants in the study groups is presented in table 2.

Participants' plasma exercise levels of serotonin ranged from $45.3 \mathrm{ng} / \mathrm{ml}$ to $103.2 \mathrm{ng} / \mathrm{ml}$ is within the normal limit as given by the manufacturer of the serotonin assay kit, used in this study, which was $40-450 \mathrm{ng} / \mathrm{ml}$. The basal concentration of plasma serotonin was increased after the exercise by $16.8 \% 18.2 \%$ in the stabilisation and treadmill walk exercise groups respectively. The back extension exercise group only showed a slight increase by $2 \%$ in the plasma serotonin after exercise testing. The basal concentration of plasma serotonin was reduced by $3.8 \%$ after 30 minutes of resting in a supine lying position.
One-way analysis of variance showed no significant difference in the basal plasma levels of serotonin among the four groups $(\mathrm{F}=1.906, \mathrm{P}=0.169)$. Within group comparison using a paired t-test showed a significant increase in the post exercise plasma levels of serotonin in the stabilisation group $(\mathrm{t}=-2.78$, $\mathrm{P}=0.009)$ and treadmill walk exercise group $(\mathrm{t}=-2.21, \mathrm{P}=0.02)$. The basal and final plasma serotonin levels in the back extension exercise and the control groups did not show any significant differences $(\mathrm{P}>0.05)$.

Thus assuming no plasma changes occurs, $10.17 \mathrm{ng} / \mathrm{ml}$ and $11.2 \mathrm{ng} / \mathrm{ml}$ of serotonin was produced by stabilisation exercise and treadmill walk exercise protocol respectively.

Table 1: Demographic variable of the participants

\begin{tabular}{|c|c|c|c|c|c|}
\hline \multicolumn{6}{|c|}{ Groups } \\
\hline & Stabilisation & Back-extension & Treadmill & Control & $\begin{array}{l}\mathrm{P} \text {-value } \\
\mathrm{N}=4\end{array}$ \\
\hline \multicolumn{6}{|c|}{ Mean \pm SD } \\
\hline Characteristics & & & & & \\
\hline Age (yrs) & $30.8 \pm 3.2$ & $26.2 \pm 4.3$ & $25.8 \pm 6.4$ & $28.5 \pm 3.9$ & 0.20 \\
\hline Weight (kg) & $56.2 \pm 6.8$ & $55.6 \pm 7.1$ & $58.4 \pm 7.4$ & $62.3 \pm 1.7$ & 0.15 \\
\hline Height (m) & $1.63 \pm 0.1$ & $1.64 \pm 0.1$ & $1.63 \pm 0.1$ & $1.67 \pm 0.1$ & 0.33 \\
\hline BMI (kg/m2) & $21.2 \pm 3.2$ & $20.8 \pm 2.9$ & $22.4 \pm 1.9$ & $21.4 \pm 1.9$ & 0.34 \\
\hline
\end{tabular}

Table 2: Participants plasma levels of serotonin

\begin{tabular}{|c|c|c|c|c|c|}
\hline \multicolumn{6}{|c|}{$\begin{array}{c}\text { Plasma levels of serotonin } \\
\text { (Mean) }\end{array}$} \\
\hline \multicolumn{6}{|c|}{$\begin{array}{l}\text { Mean } \\
\text { Difference }\end{array}$} \\
\hline Groups & & & & & \\
\hline Stabilisation & 55.8 & 66.0 & 10.2 & 5.9 & 0.01 \\
\hline Back extension & 67.4 & 68.8 & 1.4 & 0.1 & 2.39 \\
\hline Treadmill & 66.8 & 78.0 & 11.2 & 11.2 & 0.02 \\
\hline Control & 65.0 & 62.8 & 2.2 & 5.3 & 2.29 \\
\hline
\end{tabular}

Table 3: Participants plasma levels of beta-endorphin

\begin{tabular}{|c|c|c|c|c|c|}
\hline \multicolumn{6}{|c|}{$\begin{array}{l}\text { Plasma levels of beta-endorphin } \\
\text { (Mean) }\end{array}$} \\
\hline \multicolumn{6}{|c|}{ Difference } \\
\hline Groups & & & & & \\
\hline Stabilisation & 0.60 & 0.66 & 0.06 & 0.003 & 2.01 \\
\hline Back extension & 0.61 & 0.65 & 0.04 & 0.004 & 2.39 \\
\hline Treadmill & 0.57 & 0.67 & 0.10 & 0.008 & 0.07 \\
\hline Control & 0.44 & 0.43 & -0.01 & 0.005 & 2.49 \\
\hline
\end{tabular}




\section{Plasma levels of beta-endorphin.}

Plasma levels of beta-endorphin of the participants in the study groups are presented in table 3.

Participants plasma beta-endorphin levels, which ranged from $0.05 \mathrm{ng} / \mathrm{ml}$ to $1.32 \mathrm{ng} / \mathrm{ml}$ is within the normal limit as given by the manufacturer of betaendorphin kit used in this study, which ranged from $0.22 \mathrm{ng} / \mathrm{ml}$ to $3.19 \mathrm{ng} / \mathrm{ml}$. One-way analysis of variance showed no significant difference in the basal plasma levels of beta-endorphin among the groups $(\mathrm{F}=0.857, \mathrm{P}=0.483)$. A slight increase in the post exercise plasma levels of beta-endorphin of less than $0.2 \mathrm{ng} / \mathrm{ml}$ was noticed in all the exercise groups. These differences were not statistically significant in all the groups $(\mathrm{P}>0.05)$.

\section{DISCUSSION}

\section{Participants}

Twenty healthy volunteers participated in this study, this figure was considered appropriate based on the report of similar studies on the effect of exercise on pain relieving peptides (Goldfrab et al.1997; Lechin et al. 2004; Sheps et al. 1988).

The participants in this study were healthy volunteers i.e. those without a history of non-specific low back pain for at least 12 months prior to the commencement of the study. This group was used to ensure optimal muscular contraction unhindered by pain and to rule out the possibility of LBP influencing any observed changes in the levels of plasma serotonin and beta-endorphin. None of the participants was actively involved in sporting activities at professional or competitive levels.

\section{Plasma levels of serotonin}

This results of the present study suggest that in healthy volunteers, stabilisation and treadmill walk exercises may stimulate a general response similar to most of the many and varied stimuli that result in a significant increase in the secretion of serotonin into the blood. Similar alterations in the levels of serotonin after exercises and physical activity have been reported. Lechin et al. (2004) reported an increase by $15.9 \%$ in the level of plasma serotonin in healthy volunteers instructed to perform a treadmill exercise test consisting of 5 minutes walking exercises at $2 \mathrm{mph}$. In contrast, Jensen et al. (1995) reported an increase by $4 \%$ in the serum serotonin levels, of healthy volunteers, following bicycle ergometry exercise of moderate intensity. Interestingly, Jensen et al expected a higher percentage $(15 \%)$ increase in the serum concentration of serotonin since the concentration of blood platelets increased by $15 \%$, thus the discrepancy between the results of the present study and Jensen et al's may, at least in part, be due to methodological problems.

It seems that the biochemical events associated with most of the spinal based exercise used in the management of low back pain have not been reported previously. However, many reports have indicated that a combination of opioidergic and serotonergic drugs is clearly effective in reducing pain in a number of musculoskeletal conditions (Ballantyne and Mao 2003; Zense et al. 1992). It could then be that serotonin is actively involved in the potentiation of descending pain inhibitory mechanism. From a clinical perspective exercises remain one of the strategies for the exploitation of descending control to alleviate pain via the pre-synaptic action and postsynaptic action of the opioidergic, serotonergic and adrenergic systems (Millan 2002). Exercise has received attention as a result in part of the lack of available drugs that can be used over an extended period of time without risk of addiction and/or side effects (Devries 1981).

It could also be that the serotonin pain relief mechanism is linked to its potency both as analgesics and as an antidepressant. Although the exact mechanism and pathways involved in both actions still remain unclear (Atkinson 1999). It could then be assumed that the analgesic ability of serotonin is related to alleviation of depression, which can often accompany chronic pain.

\section{Plasma levels of beta-endorphin}

Participants' plasma beta-endorphin levels did not show any significant increase after exercise testing in all the exercise groups. Similar response to beta-endorphin responses to arm and leg exercises was reported by Maresh et al.
(2006). Maresh et al. (2006) examined beta-endorphin responses to arm and leg exercises with a bicycle ergometer at $60 \%$ and $80 \%$ V02 max in eighty untrained men and observed that plasma beta-endorphin levels were not different, at $60 \%$ V02 max, from the pre exercise levels in any of the participants. This could be attributed to lack of sufficient metabolic and thermal stresses necessary to potentate beta-endorphin production in response to exercises of low intensity level.

Exercise intensity of at least $70 \%$ V02 max will exceed anaerobic threshold and be associated with production of large amount of lactic acid will be required for beta-endorphin release from the plasma (Goldfrab et al. 1997). Most spinal based exercises that are being used in the management flow back disorders are of low intensity ( $<70 \%$ V02 max). It could be that spinal based exercises carried out at high intensity (> 70\% V02 max), that could lead to beta-endorphin production might be counterproductive in terms of aggravation of symptoms of pain and functional disability and this may out weigh the possible physiological benefits associated with beta-endorphin release.

\section{LIMITATIONS OF THIS STUDY}

Participants were requested to refrain from smoking and taking caffeine and/or alcohol at least 12 hours before the exercise testing, as these could influence plasma concentration of serotonin and beta endorphins. Participants' total compliance in this regard could not be guaranteed, although questions were asked to ensure their compliance prior to initial assessments and exercise testing.

\section{CONCLUSION}

The results of this study point to the fact that spinal based exercises used in the management of low back disorders e.g. spinal stabilisation exercises and treadmill walking exercises biochemical mode of action might be confined to the spinal levels and is likely to involve the activation of the serotonergic systems or perhaps involve a more complex supraspinal mechanism not yet investigated. This results informed the decision of the authors to carry out a large randomised controlled trial in which the 
effects of frequency of application of spinal stabilisation exercises on plasma serotonin levels, pain intensity, functional disability and quality of life in sub-clinical chronic low back pain was investigated.. Knowledge of the right dosage of exercises will be necessary to provide an insight into the optimal period for efficacy and also for cost effectiveness.

It is also important to mention that the therapeutic benefits of stabilisation exercise could also be derived from other mechanisms that require further investigation. There might be yet noninvestigated effects of stabilisation exercise on muscles, fascia and articular receptors in the lumbosacral segments of the spine.

\section{REFERENCES}

Atkinson H, Slater MA, Wahlgreen DR, Williams RA, Zisook S, Priutt SD, Patterson TL, Grant I, Abrasom I, Garvin SR 1999. Effects of nor adrenergic and seretoneric antidepressants on chronic low back pain intensity. Pain 83: 137-145

Ballantyne JC and Mao J 2003. Opioid therapy for chronic pain. New England Journal of Medicine 349: 1943-1953

Berkow R, Andrew JF and Mark HB 1992. The Merck Manual 16th edition, Merck Research Laboratories, Rahway, NJ, 938.

Carr DB, Bullen BA, Skrinar GS, Arnold MA, Rosenblatt M, Beitins IZ. 1981. Physical conditionin facilitates the exercise induced secretion of beta-endorphin and betalipotropin in women. New England Journal of Medicine 305:560-563

Clinical Standard Advisory Group (CSAG) 1994. Back Pain (Report of CSAG Committee on back pain chaired by Professor Michael Rosen), HSMQ London England.

De Vries HA, 1981. Tranquilizer effects of exercise. A critical review Physician Sport (1) $9: 47-55$

Farrell PA, Kjaer M, Bach FW, Gablo H, 1987. Beta-endorphin and adrenocorticotropin response to supramaximal treadmill exercise in trained and untrained males Acta Physiol Scand. 130:619-625

Goldby L, Moore A, Doust J, Trew M, 2006. A randomised controlled trial investigating the effects of musculoskeletal therapy on chronic back disorder. Spine 31 (10): 1083-1093

Goldfrab AH, Hartfield BD, Armstrong D, Potts J, 1997. Plasma beta endorphin concentration in response to intensity and duration of exercise Medical Science and Sport Exercises 22 (2):241-244.
Hides JA, Richardson CA and Jull GA 1996. Multifidus muscle rehabilitation decreases recurrence of symptoms following first episode of low back pain In: Proceedings of the 1996 National Physiotherapy Congress of Australia, Australia 43-44

Hoffman P, Jonsdottir IH, Thoren P, 1996. Activation of different opioid systems by muscle activity and exercise. New Physiol. Sci. 11:223-228

Jadad R, Cook DJ, Jones A, Klassen TP, Tugwell P, Moher M and Moher D, 1998. Methodology and reports of systematic reviews and meta-analyses: a comparison of Cochrane reviews with articles published in pare based journals JAMA 280: 278-290

Jarmukli NF, Ahn J, Iranmanesh A and Russell DC 1999. Effects of raised beta-endorphin concentration on peripheral pain and angina thresholds in patients with stable angina. Heart 82: 204-209

Jensen PN, Mooler HJ, Smith DF and Rosenberg 1995. Acute effect of exercise on human blood platelet serotonin reuptake and non-amine oxidase activity. Society of Biological Psychiatry 38:125-127

Kema IP, deVries EGE, Muskiet FAJ; 2000. Clinical Chemistry of serotonin and metabolites. Journal of chromatography: Biomedical sciences and application 747 (1-2): 33-48

Lapsley P. 1990. The economics of back pain. Back pain. An International review. Kluwer Academic Publisher Dordrecht, Boston London xxiii

Lechin F, Pardey-Maldonado B, Van derDjis B, Orozco B, Lechin AE. 2004. Circulating neurotransmitters during different wake-sleep stages in normal subjects Psychoneuroendocrinology 29: 669-685

Linton SJ 1997. Secondary prophylaxis of back pain European Journal of pain (1) 1 68-69

Mannion AF, Muntener M, Taimela S, Dvorack J, 1999. A randomised clinical trial of three active therapies for chronic low back pain Spine 24: 2435-2448

Maresh CM, Sokmen M, Kraemer WJ, Hoffman JR, Watson G, Judelson DA, Gabaree-Boulant CL, Deschens MR, vanHeest JL, Armstrong E, 2006. Pitutary adrenal responses to arm and leg exercises in untrained men European Journal of Applied Physiology 97:471-477

McMurray RG, Sheps DS, Guinan DM, 1984. Effects of naloxone on maximal stress testing in females. Journal of applied Physiology 56: 436-440

Millan MJ 2002. Descending control of pain. Progress in Neurobiology 66 353-374

O’Sullivan P, Twomey L, Allinson G, 1997. Evaluation of specific stabilising exercise in the treatment of low back pain with radiologic diagnosis of Spondylosis or spondylolysthesis Spine 22: 2959-2967
Rainville J, Jouve CA, Hartigan C, Martinez E, Limke J, Jouve C, Finno M, 2004. Exercise as a treatment for chronic low back pain. The spine Journal 1: 106-115

Riihimaki H, Viikari-Juntura E, Moneta G 1994. Incidence of sciatic pain among men in machine operating dynamic physical work and sedentary work. A three year follows up. Spine 19:138-142

Risch SV, Norvell NK, Pollock ML, Risch ED, Langer H, Fulton M, Graves JE, Leggett SH,1993. Lumbar strengthening in Chronic low back pain patients. Physiologic and psychological benefits Spine 18 (2): 232-238

Sheps DS, Koch G, Bragdon EE, Ballenger MN, 1988. The reproducibility of resting and pro exercise plasma beta-endorphin. Life Science 43, 9: 787-791

Sheps DS, Ballenger MN, De Grant G, 1995. Psychophysical responses to a speech stressor: correlation of plasma beta-endorphin concentration at rest and post psychological stress with pain threshold in patients with coronary artery disease. J Am Coll Cardiol 25:14991503

Smith I 1998. The effect of mental practice on muscle strength and EMG activity. Abstract presented at the British Psychological Society 1998.

Taylor DV, Boyajian TJ, James N, Woods D, Chicks-Damet A, Wilson AF, Sandman CA 1994. Acidosis stimulates beta- endorphin release during exercise. Journal of Applied Physiology 77; 4, 1913-1918

Van Tulder MW, Malmivaara A, Esmail R, 2000. Exercise therapy for low back pain (Chocrane review) Oxford. The Cochrane Library.

Viru A, Tendezgolskis Z, Smirnova T, 1990 Changes in beta-endorphin levels in the blood during prolonged exercise. Endocrin Exper 24:63-68

Waddell G. (1996) Low back pain: a twentieth century health care enigma. Spine 21: 28202825

Waddell G, Somerville D, Henderson I, Newton M, (1992) Objective Clinical evaluation of physical impairments in Chronic low back pain Spine 17:617

Zense M, Strumpf M, Tyrba M, 1992. Long term oral opioid therapy in patients with chronic non malignant pain J Pain Symptom Manage 7: 69-77 